\title{
Screening and Prevalence of Internal Hemorrhoids in Patients Undergoing Flexible Colonoscopy
}

Samir Abdel Azim Morsy Afifi, Waleed Younus Abu Aeshah*, Ayman Fathy Elsayed Mohammed, Ayman Magd Eldin Mohammad Sadek

Internal Medicine Department, Faculty of Medicine, Zagazig University, Egypt

*Corresponding Author: Waleed Younus Abu Aeshah, Mobile: (+20)01030866527, Email: walidabuaishay@ gmail.com

\begin{abstract}
Background: Hemorrhoids are swollen veins of the hemorrhoidal plexus that are normally present in the anal canal. Clinically detectable if the supporting connective tissue is compromised. In this study, we focused on the effectiveness and importance of colonoscopy for studying the prevalence of internal hemorrhoids.

Objective: The study aimed to evaluate the prevalence of internal hemorrhoids in patients undergoing colonoscopy for different indications.

Patients and Methods: This cross-sectional study was conducted in the Elective Gastrointestinal Endoscopy Unit, Internal Medicine Department, Faculty of Medicine, Zagazig University. The study was conducted through the period from March 2021 to Augustus 2021, and including 300 consecutive Egyptian patients who underwent a flexible colonoscopy for different reasons.

Results: In the present study, we revealed that hemorrhoids increasing with aging. The diagnostic results were internal hemorrhoids $(38.3 \%)$, colonic ulcers $(11 \%)$, inflammatory lesions $(7.3 \%)$ and mass $(7 \%)$, diverticular disease $(6 \%)$, polyps (5.7\%), and vascular malformations (1.3\%). The complaints of the patients were lower GI bleeding (41.7\%). Chronic diarrhea (17.7\%), abdominal pain (14.7\%), and chronic constipation (13.3\%) in the subsequent levels. Also, chronic anemia $(6.7 \%)$, follow-up colon polyp $(5.3 \%)$, one patient had weight loss $(0.3 \%)$ and one patient had anal pain $(0.3 \%)$.

Conclusions: We can conclude a wide prevalence of internal hemorrhoids in patients who underwent colonoscopy for various reasons. Besides, retroflexed colonoscopy can contribute to the study of the prevalence of internal hemorrhoids because it can diagnose even asymptomatic hemorrhoids. In addition, colonoscopy was found to be extremely safe and no complication was detected.
\end{abstract}

Keywords: Colonoscopy, Prevalence, Internal hemorrhoids.

\section{INTRODUCTION}

Hemorrhoid is a common benign anorectal disease in which are swollen veins present in the anal canal and become clinically detectable when the connective tissue that supports the anorectal region is damaged ${ }^{(1)}$. The symptoms of Huntington's disease (HD) vary depending on the location and type of HD. Lower gastrointestinal (GI) bleeding is the main clinical symptom ${ }^{(2)}$.

The diagnosis of hemorrhoids is made clinically through a careful digital examination. Anoscopy is performed paying particular attention to the known position of hemorrhoidal disease ${ }^{(3)}$.

There is limited data about the incidence, gender, and age distribution of internal hemorrhoids in the population especially those undergoing elective colonoscopy for different indications. Colonoscopy has an important role in the diagnosis of many anorectal diseases especially internal hemorrhoids ${ }^{(4)}$.

Worldwide, the prevalence of symptomatic hemorrhoids is estimated at $4.4 \%$ in the general population, there has been a paucity of study researches on the epidemiology of hemorrhoids, and prevalence is not well-documented ${ }^{(5)}$.

Hemorrhoids are not selective for age or sex. However, age is known to be a risk factor, and the prevalence of hemorrhoidal disease is less in underdeveloped countries ${ }^{(6)}$.

However, there has been a noticeable increase in the incidence of hemorrhoids in recent years ${ }^{(2)}$.

\section{PATIENTS AND METHODS}

This Cross-sectional study was conducted in the Elective Gastrointestinal Endoscopy Unit, Internal Medicine Department, Faculty of Medicine, Zagazig University from March 2021 to Augustus 2021.

300 consecutive Egyptian patients who underwent a flexible colonoscopy were enrolled in this study for different reasons.

\section{Inclusion criteria:}

Age from 18 to 75 years old. All patients underwent a flexible colonoscopy for different reasons as lower GI bleeding, screening and surveillance of colorectal polyps, cancers and inflammatory bowel diseases, acute and chronic diarrhea, abnormal radiological examinations, isolated unexplained abdominal pain, chronic constipation, and preoperative localization of colonic lesions.

\section{Exclusion criteria:}

Grade IV internal hemorrhoids in Goligher's classification. Age $<18$ and $>75$. Contraindications 
for colonoscopy (e.g. toxic megacolon, acute diverticulitis, fulminant colitis, free colonic perforation, inadequate colonic cleansing, severe coagulopathy, pregnancy, recent cerebral hemorrhage, recent myocardial infarction, pulmonary embolism, immediately post-colonic surgery, and patients refuse consent).

\section{Pre-colonoscopy assessment:}

All patients were subjected to the following: Full history taking, proper clinical examination, and routine laboratory investigations (CBC, RFT, LFT, and viral screen).

Preparation of the patients for colonoscopy was done as follows: All patients were asked not to take any solid foods from the day before the procedure and drink only water and clear juices. The patients were given a laxative preparation MOVIPREP (polyethylene glycol 3350, sodium sulfate, sodium chloride, potassium chloride, sodium ascorbate, and ascorbic acid), this preparation was added to 1liter water and taken as oral Solution in two doses at the day before the procedure as advised by Wilson et al. ${ }^{(7)}$, which were tolerable and effective in most of our patients.

\section{Colonoscopy procedure:}

A colonoscopy examination was performed under sedation of patients during the procedure. The patients are given fentanyl or midazolam intravenously. The average person will receive a combination of these two drugs, usually between 25 and $100 \mu \mathrm{g}$ IV fentanyl and 5-10 mg IV midazolam.

Patients were placed in the left lateral decubitus position during the procedure. The vital signs (heart rate, oxygen saturation) were closely observed by the monitor.

The first step is usually a digital rectal examination, to detect anal stricture or any rectal mass and to determine if preparation has been inadequate. The endoscope is then passed through the anus up the rectum, the colon (sigmoid, descending, transverse, ascending colon, and the cecum). The procedure was done by (OLYMPUS EVIS EXERA III CV 190) and PENTAX colonoscopies.

\section{Withdrawal criteria from the study:}

Patients were not prepared well, patients were hemodynamically unstable at the examination or during the procedure and patients did not cooperate with the procedure.

\section{Post-colonoscopy follow-up:}

All patients were observed two hours after the procedure and were discharged after full recovery.

\section{Ethical consideration:}

An approval of the study was obtained from Zagazig University Academic and Ethical
Committee. Every patient signed an informed written consent for acceptance of the procedure and sharing in this study. The work described has been carried out in accordance with The Code of Ethics of the World Medical Association (Declaration of Helsinki) for experiments involving humans.

\section{Statistical analysis}

Statistical analysis was performed by SPSS statistical software, version 25 (IBM, Chicago, Illinois, USA). The Shapiro-Wilk test was used to determine whether the data were distributed normally or not. Continuous data were described as median (IQR) with the minimum, and maximum for non-normally distributed variables $(\mathrm{P}<0.05)$. Categorical data were described with absolute and relative frequencies $(\mathrm{N} \%)$. Categorical data were analyzed by the Chi-square test or Fisher's exact test for small-expected cell frequencies. The statistical significance level was set at $\mathrm{P} \leq 0.05$.

\section{RESULTS}

300 participants were involved in the present study. The median age of the participants was 46 years old (IQR: $34-60)$ and ranged from 18 to 75 years. The majority [157 (52.3\%)] were males, and $143(47.7 \%)$ were female. Twenty-five patients $(8 \%)$ of 300 participants presented with external hemorrhoids (Table 1). 185 patients $(61.7 \%)$ had no internal hemorrhoids. Additionally, 115 patients (38.3\%) had internal hemorrhoids (Table 2).

The complaints of the patients were lower GI bleeding (41.7\%), chronic diarrhea (17.7\%), abdominal pain (14.7\%), and chronic constipation $(13.3 \%)$ in the subsequent levels. Also, chronic anemia $(6.7 \%)$, follow-up colon polyp $(5.3 \%)$, one patient $(0.3 \%)$ had weight loss and one patient $(0.3 \%)$ had anal pain (Table 3). The three most frequent other diagnostic results were colonic ulcers (11\%), inflammatory lesions $(7.3 \%)$, mass $(7 \%)$, diverticular disease (6\%), polyps (5.7\%), and vascular malformations (1.3\%). One hundred and eighty-five $(61.7 \%)$ showed normal colonoscopy (Table 4).

Table (1): Demographic characteristics of study participants.

\begin{tabular}{|l|l|c|}
\hline \multicolumn{2}{|c|}{ Variables } & Outcome(n=300) \\
\hline $\begin{array}{l}\text { Age } \\
\text { (years) }\end{array}$ & Median (IQR) & $46(34-60)$ \\
\cline { 2 - 3 } Sex, N (\%) & $18-75$ \\
\hline $\begin{array}{l}\text { Males } \\
\text { Females }\end{array}$ & $157(52.3 \%)$ \\
\hline External hemorrhoid, N & $143(47.7 \%)$ \\
$(\%)$ & \\
Yes & $25(8 \%)$ \\
No & $275(91.7 \%)$ \\
\hline
\end{tabular}

Data presented as N (\%) for categorical data or Median [IQR] with range for continuous data 
Table (2): The prevalence of internal hemorrhoids in study participants

\begin{tabular}{|l|c|c|}
\hline \multicolumn{1}{|c|}{ Variables } & Frequency & $\begin{array}{c}\text { Percentage } \\
(\boldsymbol{\%})\end{array}$ \\
\hline NO & 185 & 61.7 \\
\hline $\begin{array}{l}\text { Internal } \\
\text { hemorrhoids }\end{array}$ & 115 & 38.3 \\
\hline
\end{tabular}

Table (3): The complaints of study participants

\begin{tabular}{|l|c|c|}
\hline \multicolumn{1}{|c|}{ Variables } & Frequency & $\begin{array}{c}\text { Percentage } \\
(\%)\end{array}$ \\
\hline $\begin{array}{l}\text { Lower GI } \\
\text { bleeding }\end{array}$ & 125 & 41.7 \\
\hline Chronic diarrhea & 53 & 17.7 \\
\hline Abdominal pain & 44 & 14.7 \\
\hline $\begin{array}{l}\text { Chronic } \\
\text { constipation }\end{array}$ & 40 & 13.3 \\
\hline Chronic anemia & 20 & 6.7 \\
\hline Follow up & 16 & 5.3 \\
\hline Weight loss & 1 & 0.3 \\
\hline Anal pain & 1 & 0.3 \\
\hline
\end{tabular}

Table (4): Clinical diagnostic results observed in study participants.

\begin{tabular}{|l|c|c|}
\hline \multicolumn{1}{|c|}{ Variables } & Frequency & $\begin{array}{c}\text { Percentage } \\
(\mathbf{\%})\end{array}$ \\
\hline No & 185 & 61.7 \\
\hline Colonic ulcer & 33 & 11.0 \\
\hline $\begin{array}{l}\text { Inflammatory } \\
\text { lesions }\end{array}$ & 22 & 7.3 \\
\hline Mass & 21 & 7.0 \\
\hline Diverticular disease & 18 & 6.0 \\
\hline Polyps & 17 & 5.7 \\
\hline $\begin{array}{l}\text { Vascular } \\
\text { malformations }\end{array}$ & 4 & 1.3 \\
\hline
\end{tabular}

\section{DISCUSSION}

Hemorrhoid, a common anorectal disease and lower GIT bleeding, is one of the main clinical symptoms with or without hemorrhoidal prolapse. However, the symptoms of HD vary depending on the location and type of hemorrhoids. There has been a noticeable increase in the incidence of hemorrhoids in recent years causing affection on patients' life ${ }^{(2)}$.

Colonoscopy can be used for many reasons such as lower gastrointestinal bleeding, abdominal pain, unexplained changes in bowel habits, suspicion of malignancy or a radiological abnormality, history of polyps, cancer colon, and those with a family history of cancer colon ${ }^{(8)}$.

In the present study, the median age of the participants was 46 years old (IQR: $34-60$ ) and ranged from (18 to 75) years, we revealed that hemorrhoids increasing with aging. Lee $\boldsymbol{e t} \boldsymbol{a l} .{ }^{(9)}$ also reported that the prevalence of hemorrhoids is already high by the age of 30 . This accords with our findings that the anchoring mechanism of the rectal mucosa deteriorates with advancing age. In certain patients, hemorrhoids may appear earlier than others, just like wrinkles on the face or sagging skin. Eventually, everybody will have hemorrhoids because the anchoring system of the anal mucosa deteriorates as a part of the aging process; however, not everybody will have symptoms of hemorrhoids. Environmental or other unknown factors, yet unknown, may also play a role ${ }^{(\mathbf{1 0})}$.

The univariate analysis also showed that the major symptoms of the patients were lower GI bleeding (41.7\%), chronic diarrhea (17.7\%), abdominal pain (14.7\%), chronic constipation (13.3\%), and chronic anemia $(6.7 \%)$. Elbatea et al. ${ }^{(11)}$ showed that $(63 \%)$ of patients presented with abdominal pain, (50\%) lower GI bleeding, (48\%) presented with diarrhea, 30\% with constipation, (27\%) presented with weight loss, and $22 \%$ presented with iron deficiency anemia. Our study showed that hemorrhoids was the commonest lesion $(38.4 \%)$ followed by colonic ulcers (11\%), inflammatory lesions $(7.3 \%)$, mass $(7 \%)$, diverticular disease (6\%), polyps (5.7\%), and vascular malformations $(1.3 \%)$. While $61.7 \%$ had a normal colonoscopy. Mostafa et al. ${ }^{(8)}$ who also used colonoscopy examination for different reasons found that hemorrhoids were the commonest lesion in $27.6 \%$ followed by non-specific colitis (20.4\%), inflammatory bowel disease $(11.2 \%)$, carcinoma $(10.4 \%)$, and then polyp $(0.4 \%)$. Elbatea et al. ${ }^{(11)}$ also used colonoscopy examination for different reasons, and the final diagnosis in that study was inflammatory bowel disease (25\%), internal hemorrhoids (18\%), CRC (15\%), benign polyps $(9 \%)$, diverticular disease $(2 \%)$, and vascular malformations $(0.2 \%)$.

In addition, Olokoba et al. ${ }^{(12)}$ reported that the commonest pathologies found at colonoscopy examination were cancer colon followed by diverticulosis and polyps. Ghazzawi et al. ${ }^{(13)} \mathrm{did}$ a similar study done at King Hussein Medical Center in Jordan; the most common abnormal findings were colonic cancer in $29 \%$, colonic polyps in $24 \%$, and IBD in $16 \%$. The changeable incidence and prevalence of diseases in different areas, and the relatively different numbers and ages of the population in their study might explain the difference in final colonoscopy results.

One of the limitations in the current study was the cross-sectional design that cannot provide follow-up data for the patients. Besides, it did not study the effectiveness of colonoscopy in treating hemorrhoids, as in some studies as in Fukuda et al. ${ }^{(4)}$.

\section{CONCLUSION}

We concluded that there was a wide prevalence of internal hemorrhoids in patients who underwent colonoscopy for various reasons. Besides, the retroflexed colonoscopy can contribute to the study of the prevalence of internal hemorrhoids because it can diagnose even asymptomatic hemorrhoids. In addition, colonoscopy was found to be extremely safe, and no 
complication was detected. The safety of colonoscopy has been proved in many other studies all over the world.

\section{RECOMMENDATION}

Other future studies are required to explain the association of internal hemorrhoids with many diseases. More future studies are needed on a large scale of patients' number to explain why some patient has external hemorrhoids while another patient has internal hemorrhoids and which predicting patient in developing hemorrhoids.

Financial support and sponsorship: Nil.

Conflict of interest: Nil.

\section{REFERENCES}

1. Schleinstein $\mathrm{H}$, Averbach $\mathrm{M}$, Averbach $\mathrm{P}$ et al. (2019): Endoscopic band ligation for the treatment of hemorrhoidal disease. Arq Gastroenterol., 56 (1): $22-$ 27.

2. Han X, Xia F, Chen G et al. (2021): Superior rectal artery embolization for bleeding internal hemorrhoids. Tech Coloproctol., 25 (1): 75-80.

3. Mott T, Latimer K, Edwards C (2018): Hemorrhoids: Diagnosis and Treatment Options. Am Fam Physician, 97 (3): 172-9.

4. Leighton J, Shen B, Baron T et al. (2006): ASGE guideline: endoscopy in the diagnosis and treatment of inflammatory bowel disease. Gastrointest Endosc., 63 (4): 558-65.

5. Aishwarya A, Kantham T, Manikavasakam K et al. (2018): A scientific review of moolam (ano rectal diseases)-yugis version. Int J Ayurveda Pharma Res., 6
(3): $37-46$.

6. Jameson J (2018): Harrison's principles of internal medicine. McGraw-Hill Education. https://www.worldcat.org/title/harrisons-principles-ofinternal-medicine/oclc/990065894

7. Wilson R, Yasmin F, Robinson K (2019): Preparing for your colonoscopy with MoviPrep. https://elht.nhs.uk/application/files/4715/6758/9952/P HARMACY-001-moviprep-2019. pdf

8. Mostafa E, Metwally A, Hussein S (2018): Inflammatory Bowel Diseases Prevalence in Patients Underwent Colonoscopy in Zagazig University Hospitals. Afro-Egyptian J Infect Endem Dis., 8 (2): 81-87.

9. Lee J, Kim H, Kang J et al. (2014): Factors associated with hemorrhoids in korean adults: korean national health and nutrition examination survey. Korean J Fam Med., 35 (5): 227-232.

10. Mostafa E, Metwally A, Hussein S et al. (2018): Inflammatory Bowel Diseases Prevalence in Patients Underwent Colonoscopy in Zagazig University Hospitals. Hum Dev Adulthood, 8 (2): 81-87.

11. Elbatea H, Enaba M, Elkassas G et al. (2011): Indications and outcome of colonoscopy in the middle of Nile delta of Egypt. Dig Dis Sci., 56 (7): 2120 2123.

12. Olokoba A, Obateru O, Bojuwoye $M$ et al. (2013): Indications and findings at colonoscopy in Ilorin, Nigeria. Niger Med J J Niger Med Assoc., 54 (2): 111116.

13. Ghazzawi I, Ajlouni Y, Smadi B et al. (2010): Colonoscopy at King Hussein Medical Center; indications, effectiveness, safety and outcome. Jord Roy Med Serv., 17 (1): 15-20. 